University of Nebraska - Lincoln

DigitalCommons@University of Nebraska - Lincoln

Michigan Bovine Tuberculosis Bibliography and

Database

Wildlife Disease and Zoonotics

1994

\title{
Status of bovine tuberculosis in North America
}

M.A. Essey

United States Department of Agriculture Animal and Plant Health Inspection Services, Veterinary Services, Room 729, 6505 Belcrest Road, Hyattsville, MD

M.A. Koller

Agriculture Canada Division of Animal Health Ottawa, Ont., Canada KIA OY9

Follow this and additional works at: https://digitalcommons.unl.edu/michbovinetb

Part of the Veterinary Medicine Commons

Essey, M.A. and Koller, M.A., "Status of bovine tuberculosis in North America" (1994). Michigan Bovine Tuberculosis Bibliography and Database. 39.

https://digitalcommons.unl.edu/michbovinetb/39

This Article is brought to you for free and open access by the Wildlife Disease and Zoonotics at DigitalCommons@University of Nebraska - Lincoln. It has been accepted for inclusion in Michigan Bovine Tuberculosis Bibliography and Database by an authorized administrator of DigitalCommons@University of Nebraska Lincoln. 


\title{
Status of bovine tuberculosis in North America
}

\author{
M.A. Essey ${ }^{\mathrm{a}, *}$, M.A. Koller ${ }^{\mathrm{b}}$ \\ ${ }^{a}$ United States Department of Agriculture Animal and Plant Health Inspection Services, Veterinary Services, \\ Room 729, 6505 Belcrest Road, Hyattsville, MD 20782, MD. USA \\ ${ }^{\mathrm{b}}$ Agriculture Canada Division of Animal Health Ottawa, Ont., Canada KIA OY9
}

(Accepted 6 January 1994)

\begin{abstract}
The eradication of bovine tuberculosis from North America is in the advanced stages as Canada and the United States struggle to remove the last vestiges of the disease from the domestic livestock population. Canada realistically anticipates total eradication from the national cattle herd within the next few years. The United States must yet effectively deal with the increased tuberculosis exposure potential from imported steers and from bovine tuberculosis newly discovered in its captive cervid industry. This paper reviews the history and development of tuberculosis eradication programs in North America. The basic evolution is described from area testing to slaughter surveillance with follow-up epidemiological investigations as the program foundation. The current status of both countries is described and recognized deterrents to final eradication are discussed.
\end{abstract}

Key words: Mycobacterium bovis; Cattle; Tuberculosis, bovine; Epidemiology; Eradication

\section{Introduction}

The United States' and Canada's experience in the eradication of bovine tuberculosis in North America has been strikingly similar in many parameters: initial disease prevalence, onset and progress of program, and the philosophies underlying program policies. Only now are the major differences in status beginning to emerge as both countries reach the threshold of the final eradication of bovine tuberculosis from the domestic livestock population of North America. Both countries are currently experiencing apparent widespread bovine tuberculosis in their captive ungulate industry, the epidemiological significance of which has yet to be accurately assessed. Canada is better prepared to deal with this new problem whereas the United States must first seek authorities and develop regulations to do

\footnotetext{
${ }^{*}$ Corresponding author
} 
so. Also, the United States must deal with formidable barriers to eradication not present in Canada, such as the continual influx of tuberculosis exposed steers from Mexico and certain areas of the country in which the disease is considered to be endemic.

\section{United states}

The National Cooperative State-Federal Bovine Tuberculosis program was established in the United States in 1917. The most important event leading to the new program was the onset of mandatory Federal meat inspection in 1906, which itself was a product of the high incidence of tuberculous carcasses seen on the nation's kill floors. The inspection procedure of the time was almost specifically designed for the detection of tuberculosis, and that aspect of the inspection has remained virtually unchanged to this day. In 1917 the prevalence of bovine tuberculosis was estimated at about $5 \%$ in cattle and almost $15 \%$ in swine - making it by far the most prevalent infectious disease in the nation's livestock population. In 1917 approximately 200000 cattle carcasses were retained at slaughter for tuberculosis, of which about 50000 were condemned in less than 10 million animals inspected. Tuberculosis was also the most prevalent infectious disease in the human population with a significant share of the cases attributed to $M$. bovis.

The program began as an eradication program with the provision of indemnity for owners of animals destroyed because of tuberculosis and has never deviated from the eradication goal. From the onset the program provided for " area accreditation status' ' based on program progress as measured by prevalence, and 'accredited-free herds"' were established to provide sources of tuberculosis-free replacement cattle. Area testing provided the principal means of surveillance for the first 50 years, during which the disease prevalence in the United States was reduced from almost $5 \%$ to less than $0.3 \%$. Area testing consisted of tuberculin testing $15 \%$ of a State's cattle herds each year, so that in theory during a 6-year accreditation period all of each State's cattle herds would have been tested at least once. By 1940, all States had achieved Modified-Accredited State status, meaning that in no State did the incidence of bovine tuberculosis exceed $0.5 \%$.

In 1965, program emphasis changed significantly from area testing to slaughter surveillance. The new program was based on initial detection of infected herds by tracing cattle found with tuberculosis on slaughter examination to their infected herd of origin. An epidemiological investigation followed with the intent of locating and evaluating for tuberculosis all herds associated with the index herd. This surveillance method soon proved to be a very efficient, cost effective procedure, permitting for the first time the ability to work ahead of the disease. Tuberculosis exposed animals traced to new herds were evaluated for disease and removed from these herds before disease-spread had occurred.

Infected herd depopulation was also initiated as a program element in 1965. This was based on the realization that an estimated $30 \%$ of all infected herds following a test and slaughter program were found to be still infected one or more years following their release from quarantine. The depopulation of infected and exposed herds has always been the owner's option. The decision is an economic one based on indemnity provisions of the Code of Federal Regulations which currently favors beef herd depopulation over dairy herds. The national goal is depopulation of $95 \%$ of all infected herds and even more 
importantly the destruction of virtually all tuberculosis exposed cattle traced to new herds.

Bovine Tuberculosis Accredited-Free State status proved difficult to attain in requiring 5-year freedom from confirmed tuberculosis and adherence to all provisions of the Bovine Tuberculosis Eradication Uniform Methods of Rules (UMR). The UMR states the minimum standards under which States qualify for and retain accreditation status. The UMR is reviewed annually by the Tuberculosis Committee of the United States Animal Health Association and is amended periodically as deemed appropriate to meet program needs. New Hampshire became our first Accredited Free State in 1964, almost a quarter century from the Nation's landmark attainment of Modified Accredited States in 1940. By 1975, over a decade later, only four States had achieved 'Free"' status, the chief hurdle not being 5 years of freedom from tuberculosis, but meeting the severe standards of the UMR requiring the recording of the individual identification of all adult cattle purchased and sold.

The prevalence of bovine tuberculosis infected herds in the United States is presently estimated at $0.003 \%$. The benefits gained by the total investment in the eradication effort are almost beyond calculation but can be estimated in considering the positive impact of bovine tuberculosis eradication in the slaughtering industry today and also upon the public health.

- For the past 10 years the United States has averaged 130 carcasses per year in which mycobacteriosis has been confirmed by laboratory examination of suspicious tuberculous lesions submitted from regular kill cattle. Over that period only 1300 carcasses were found affected in over 360000000 carcasses inspected. This extrapolates generously to a $\$ 1300000$ loss for the 10 -year period, averaging a $\$ 130000$ loss per year.

- $M$. bovis has been eradicated from the swine population for over 20 years, causing no loss to the industry.

- $M$. bovis is not known to exist in any other traditional species of domestic animals on United States farms.

- $M$. bovis is not known to exist in any species of wildlife or feral species.

- $M$. bovis tuberculosis in humans has been a historical disease in the United States for many years. It is not known to exist in residents except those recently immigrated to the United States from high-prevalence countries.

Fig. 1 shows the tuberculosis status of States of which 41 plus the U.S. Virgin Islands are Accredited Free. Nine States, plus Puerto Rico, have Modified Accredited status. Of these, only Tennessee has achieved at least 5 years freedom from tuberculosis and is eligible for consideration for Free status. The State of Hawaii was eligible for Free status consideration in 1992.

In the 1991 fiscal year, 16 tuberculous herds were detected which included 13 infected herds and 3 exposed. Six of these tuberculous herds were in Texas with two each in New Mexico and North Carolina. The map in Fig. 2 shows the distribution of 83 confirmed infected herds detected from 1982 to 1991 , which averaged 8.5 herds per year. The 83 herds were located in 23 States. The widespread distribution of infected herds is more telling than the low numbers of herds involved and highlights the importance of tuberculosis-exposed animal movements in disease spread. Only three north-eastern States are not contiguous with an $M$. bovis State. 


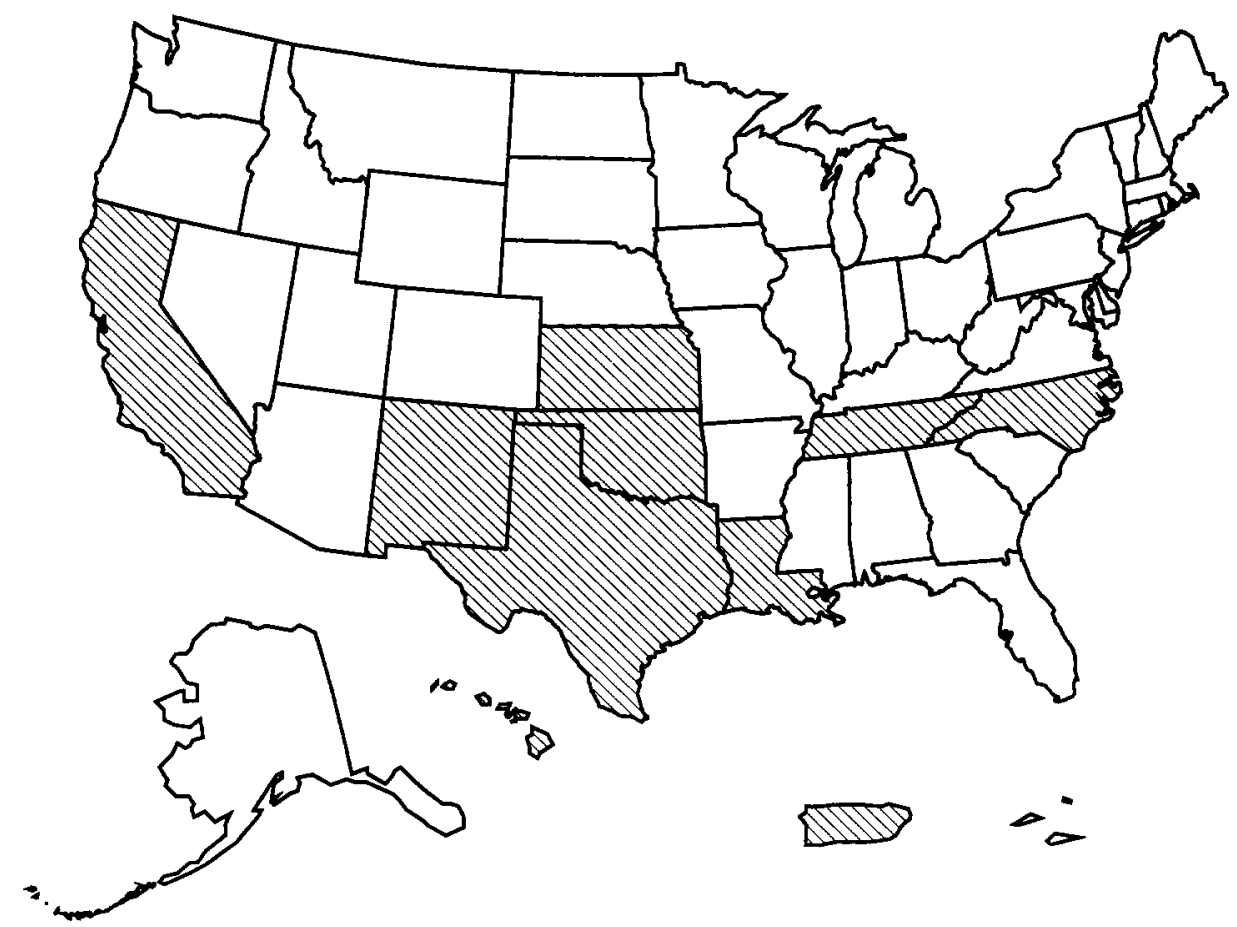

Fig. 1. The status of bovine tuberculosis in the United States for the 1991 fiscal year. The unshaded States (41) plus the Virgin Islands are Accredited Free and the shaded States (9) plus Puerto Rico are Modified Accredited.

Most infected and exposed herds in the United States are detected by epidemiological means rather than by routine testing such as for sale purposes. Epidemiological means include slaughter tracebacks, epidemiological tracing, adjacent and contact herd testing, designated highrisk area testing, and annual retests following quarantine release of infected herds not depopulated. During the 10-year period (1982-1991), 117 (96\%) of the 122 infected and exposed herds were detected by epidemiological means. In only 5 cases was infection detected by routine testing which included testing for sale purposes ( 3 herds) and testing for milk ordinance ( 2 herds). The depopulation of tuberculous herds is presently considered as one of the most important elements in the National program. To illustrate the tenacity of $M$. bovis as a herd disease agent, during the period 1981-1990 a total of 129 tuberculous herds were detected, of which 111 (86\%) were depopulated. Of the 18 herds that were not depopulated and eventually released from quarantine, bovine tuberculosis was subsequently detected in 9 .

\subsection{Slaughter surveillance}

Slaughter surveillance in the United States is the submission by Federal and State meat inspection veterinarians of suspicious tuberculous lesions and thoracic granulomas not necessarily having the appearance of tuberculosis. The optimum submission rate of 1 lesion per 2000 adult cattle inspected at slaughter was established in 1972 based on the condem- 


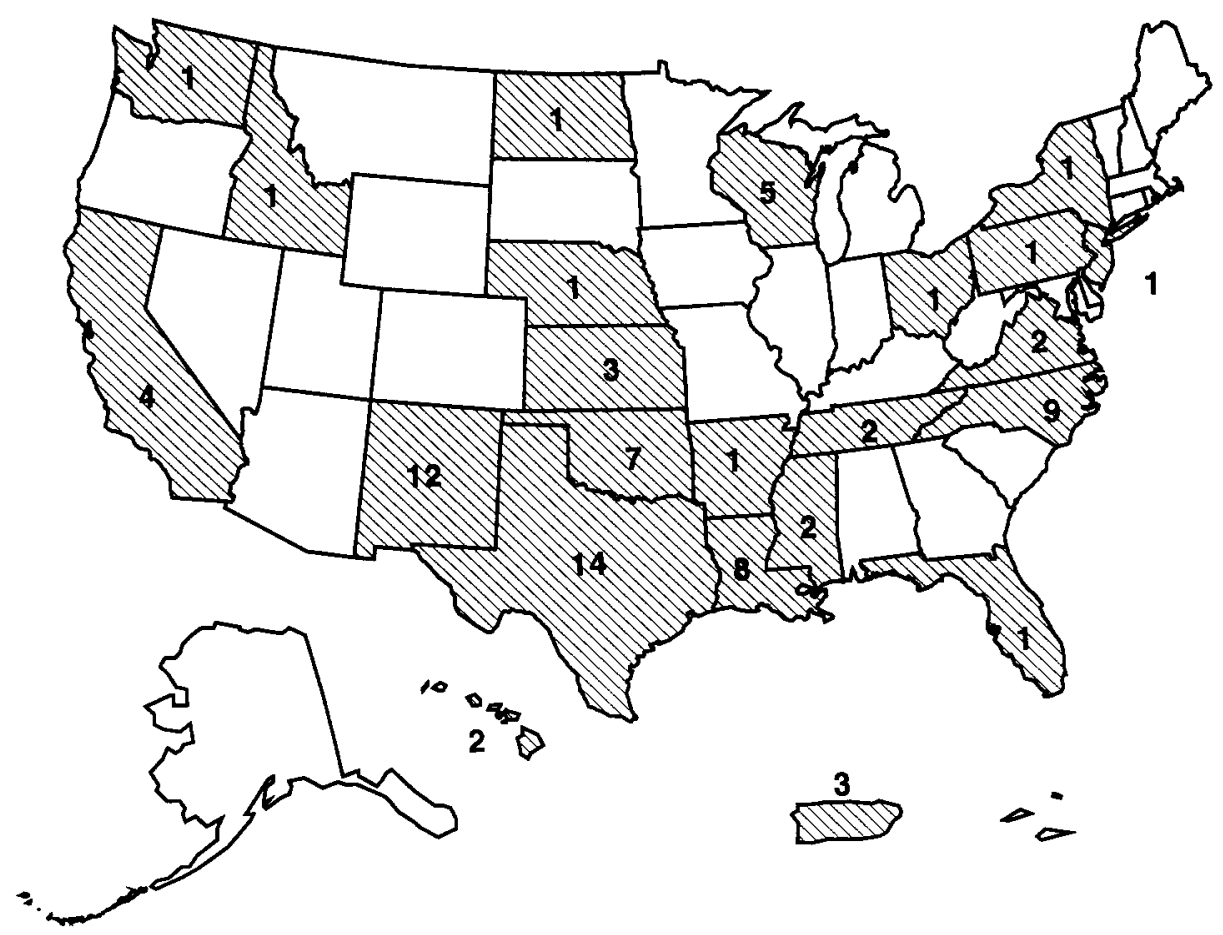

Fig. 2. Distribution of tuberculosis infected cattle herds in the United States for the period 1982-1991. Infected herds were detected in the 23 shaded States with the number of herds within each state indicated.

nation rates reported annually for all types of granulomatous conditions, e.g., coccidioidomycosis, actinobacillosis, carcinoma, etc. The attainment of this goal in the average of 36 million cattle inspected annually has been very difficult. In our peak year, 1989, the total submission of 4468 specimens represented only $34 \%$ achievement of the optimum rate. The number of cases found positive by laboratory examination totaled 1100 (5.7\% of submissions) during the 8-year period 1983-1990 giving an average of 138 cases per year. The prevalence of tuberculosis in regular slaughter cattle by tuberculosis confirmed lesions detected is $0.0004 \%$.

Bovine tuberculosis in Cervidae was recognized as a potential problem in late 1990 with the report from Canada of the possible incrimination of one or more U.S. cervid herds as the possible source of $M$. bovis in a Canadian elk herd. The U.S. investigation led to $M$. bovis confirmation in one possible source herd and to two additional herds linked by elk movements. Increased awareness and improved testing standards have resulted in the confirmation of bovine tuberculosis in ten captive cervid herds to date and to two additional herds in which confirmation is pending (Fig. 3). Also, two infected cattle herds have been discovered that apparently had acquired disease by association with $M$. bovis infected elk. These are adjacent cattle herds in the State of Nebraska, an Accredited Free State which status has been suspended and will be lost upon the isolation of $M$. bovis from the second cattle herd. 


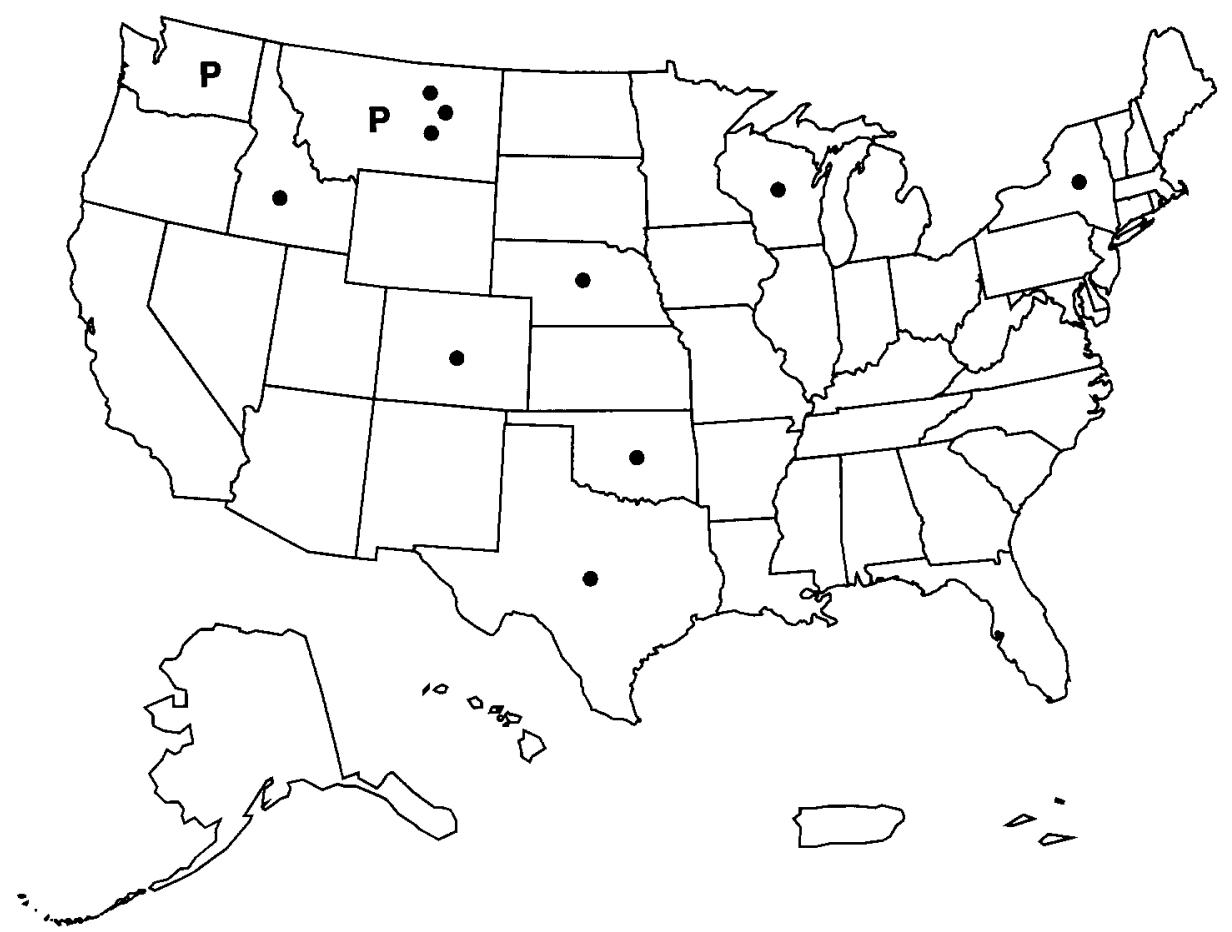

Fig. 3. The location of cervine herds in the United States infected with bovine tuberculosis in the 1991 fiscal year. - Infected, P - Pending.

\subsection{Deterrents to tuberculosis eradication}

The ongoing importation of steers from Mexico presents an ever increasing exposure potential to resident cattle herds. Approximately 1 million steers enter the United States annually, of which approximately $0.01 \%$ are found with tuberculosis at slaughter. During the past 10 years, about $66 \%$ of all tuberculous cattle found on slaughter surveillance have traced to Mexico. These steers run on pastures for 6 to 8 months prior to entering feedlots from which they eventually move directly to slaughter. Despite the apparently high-risk potential of this situation, only one infected herd in the United States has been conclusively attributed to exposure to infected Mexican steers.

Certain tuberculosis endemic areas are recognized in the United States. These are defined as areas in which continual outbreaks of bovine tuberculosis can be predicted because of (1) the distribution of tuberculosis-exposed animals which identity had been lost, (2) peculiar features of the area or the existence of husbandry practices that deter efforts to eliminate disease, or (3) large infected dairy herds which are difficult to free of tuberculosis and are not depopulated. Also, the tuberculosis problem in U.S. captive Cervidae has not yet been accurately assessed, nor has the problem of $M$. bovis infection in zoos and exotic animal collections. Clearly, all of these recognized problem areas must be effectively dealt with if the final eradication of bovine tuberculosis in the United States is to be achieved. 
Each of these problem areas will require intensified program procedures, each with its own specific modifications for successful eradication.

\section{Canada}

Meat inspection in Canada was established in 1907, at which time the prevalence of bovine tuberculosis in Canadian cattle was estimated at about $4 \%$. The Canadian tuberculosis eradication program was established in 1923. The initial plan encompassed a Restricted Area Plan in which the area tuberculin test was the prominent surveillance method. The milestone achievement of $0.11 \%$ prevalence was achieved in 1961 , by which time 50 million tests had been applied with 400000 reactors slaughtered at the cost of $\$ 15000000$ in indemnity.

The low prevalence of disease achieved through area testing led, in 1978, to the adoption of a program based on slaughter surveillance. More than $95 \%$ of Canada's 3 million annual cattle slaughter pass through federally-inspected abattoirs. The target granulomatous lesion submission rate was set at 1 lesion submitted for each 2000 adult cattle inspected. This level of lesion submission was soon met and is presently running at almost $200 \%$ of the national goal. All lesions found compatible for mycobacteriosis on histopathology result in a field investigation. Herds found infected are fully investigated with the intent of finding and eradicating all possible epidemiological linkages.

The depopulation of tuberculous-exposed animals became an important element in the Canadian program beginning in 1978. This followed a major program review and the findings of a simulated computer model that predicted a significantly reduced period for eradication provided all infected herds were depopulated. The success of this approach was demonstrated by the number of infected herds detected during the period 1982 to 1991 ; a total of 36 herds for an average of less than 4 herds per year. Only 9 infected herds have been detected in the past 5 years.

\subsection{Current status}

Of the 10 political provinces that constitute the country of Canada, 8 are tuberculousfree areas. Free areas are those which have a satisfactory performance in the preceding evaluation and have been free of bovine tuberculous in cattle during the preceding 5 years. One province (Manitoba) is currently under Suspended Free status, having had an infected herd in 1991. Free status may be reinstated after 1 year provided the outbreak is eradicated and no new cases occur. Only Quebec Province currently has Accredited Area status. Provided no new cases occur, Quebec Province will be eligible for Free status in 1994.

\subsection{Captive ungulates}

Canada's comprehensive program for the eradication of bovine tuberculosis in captive ungulates was implemented in 1989. The ungulate program includes Cervidae and the North American bison. The program includes on-the-farm testing annually in provinces experiencing tuberculosis and at 3-year intervals in nonproblem areas. Ungulate herds in which 
Table 1

Infected captive ungulate herds in Canada: 1985 to July 1991

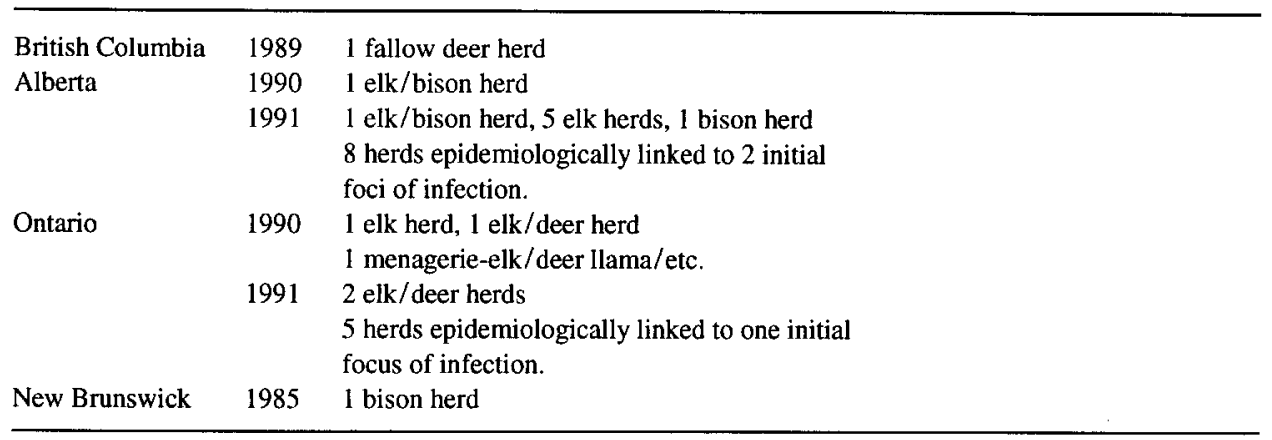

M. bovis has been confirmed are depopulated. The program is the same as for cattle with regard to epidemiological investigations of infected herds, tracing of sales and possible source herds, perimeter testing, etc. Accredited area status for tuberculosis has not yet been established for captive ungulates which as yet do not affect area status for cattle. Table 1 lists the 16 captive ungulate herds in which $M$. bovis was detected during the period 1985 through July 1991.

Bovine tuberculosis in Canadian wildlife is believed to exist only in bison in the Wood Buffalo National Park located in the far northern Alberta province, extending into the Northwest Territory. A National effort is underway to determine the basic course for dealing with this disease problem of which herd depopulation is one of the considerations.

\section{Conclusion}

Identified deterrents to the eradication of $M$. bovis from the North American continent although formidable are considered manageable. Bovine tuberculosis is not a controversial disease and the eradication goal has never been seriously challenged, either in the United States or in Canada. Required program enhancements include improved slaughter surveillance, redoubled investigating efforts, and, most importantly, new regulations governing the management and movement of tuberculosis-exposed animals intrastate, interstate, and internationally. 